\title{
Desafios de estudantes concluintes do curso de bacharelado em enfermagem, diante do estágio supervisionado e a pandemia da Covid-19
}

Challenges of students concluding the nursing bachelor's course, before the supervised internship and the pandemic of the Covid-19

Retos de los alumnos que hacen el curso de bachillerato en enfermería, antes de las prácticas supervisadas y la pandemia del Covid-19

Recebido: 30/05/2021 | Revisado: 07/06/2021 | Aceito: 08/06/2021 | Publicado: 21/06/2021

\author{
Cristiane de Lima Moreira \\ ORCID: https://orcid.org/0000-0002-3468-9382 \\ Faculdade Cristo Rei, Brasil \\ E-mail: crisvictorisa2018@gmail.com \\ Thiarles Cristian Aparecido Tonon \\ ORCID: https://orcid.org/0000-0003-0029-3758 \\ Faculdade Cristo Rei, Brasil \\ E-mail: profthiarlestonon@gmail.com
}

\begin{abstract}
Resumo
O presente estudo tem como temática os desafios enfrentados pelos discentes do curso de enfermagem durante a realização do estágio diante da pandemia do COVID-19. Tal tema consiste em uma discussão atual e necessária, em face das dificuldades encontradas mediante as mudanças no ensino, com a adoção das aulas remotas e da instabilidade do sistema de saúde onde diversos estudantes atuaram e realizaram seus estágios contribuindo para o enfrentamento dos milhares de casos de contaminação pelo vírus SARS-CoV-2. A presente pesquisa formulou-se como um estudo bibliográfico, exploratório e qualitativo que apresenta como objetivo geral evidenciar o contexto acadêmico referente ao estágio supervisionado do curso de Bacharelado em Enfermagem, durante o período pandêmico da COVID-19, revelando as dificuldades e limitações encontradas pelos discentes no campo de atuação. Acerca dos resultados obtidos, esclarece que foi verificado que tanto os discentes como os docentes do curso de enfermagem enfrentaram dificuldades de acesso, conhecimento e concentração diante da utilização dos recursos digitais, bem como presenciaram momentos de insegurança, medo, impotência e angústia frente a atuação na linha de frente no combate aos casos de COVID-19. Dessa forma, conclui-se que o contexto atual provocou diversas reflexões, principalmente no campo da educação que necessitou reformular e adaptar suas metodologias afim de promover a continuidade do ensino profissional e acadêmico. É importante ressaltar que houve aspectos positivos diante desse momento, onde aqueles estudantes que se disponibilizaram a atuar frente a linha de frente dos hospitais vivenciaram situações de luta, alegria e superação.
\end{abstract}

Palavras-chave: Estágio; Enfermagem; COVID-19; Aulas remotas.

\begin{abstract}
The present study has as its theme the challenges faced by nursing students during the internship in the face of the COVID-19 pandemic. This theme is a current and necessary discussion, given the difficulties encountered by the changes in education, with the adoption of remote classes and the instability of the health system where several students worked and carried out their internships, contributing to the confrontation of thousands of cases of contamination by the SARS-CoV-2 virus. This research was formulated as a bibliographical, exploratory and qualitative study that has as its general objective to highlight the academic context regarding the supervised internship of the Bachelor of Nursing course during the COVID-19 pandemic period, revealing the difficulties and limitations encountered by students in the field. Regarding the results obtained, it clarifies that it was found that both the students and the professors of the nursing course faced difficulties in accessing, knowledge and concentration regarding the use of digital resources, as well as witnessed moments of insecurity, fear, impotence and anguish regarding the performance in the front line in combating cases of COVID-19. Thus, it is concluded that the current context provoked several reflections, mainly in the field of education, which needed to reformulate and adapt its methodologies in order to promote the continuity of professional and academic education. It is important to emphasize that there were positive aspects in this moment, where those students who made themselves available to work in front of the hospitals' front line experienced situations of struggle, joy and overcoming.
\end{abstract}

Keywords: Phase; Nursing; COVID-19; Remote classes. 


\begin{abstract}
Resumen
El estudio presente tiene como tema los desafíos que enfrentan los estudiantes de enfermería durante la pasantía ante la pandemia COVID-19. Este tema es una discusión actual y necesaria, dadas las dificultades encontradas por los cambios en la enseñanza, con la adopción de clases a distancia y la inestabilidad del sistema de salud donde varios estudiantes trabajaron y realizaron sus pasantías, contribuyendo al enfrentamiento de miles de casos. de contaminación por el virus SARS-CoV-2. Esta investigación se formuló como un estudio bibliográfico, exploratorio y cualitativo que tiene como objetivo general resaltar el contexto académico en torno a la pasantía supervisada de la carrera de Licenciatura en Enfermería durante el período pandémico del COVID-19, revelando las dificultades y limitaciones encontradas por los estudiantes en el campo. En cuanto a los resultados obtenidos, aclara que se encontró que tanto los estudiantes como los profesores de la carrera de enfermería enfrentaron dificultades de acceso, conocimiento y concentración con respecto al uso de los recursos digitales, así como presenciaron momentos de inseguridad, miedo, impotencia y angustia. sobre el desempeño en primera línea en la lucha contra los casos de COVID-19. Así, se concluye que el contexto actual provocó varias reflexiones, principalmente en el campo de la educación, que necesitó reformular y adecuar sus metodologías a fin de promover la continuidad de la formación profesional y académica. Es importante resaltar que hubo aspectos positivos en este momento, donde aquellos estudiantes que se pusieron a disposición para trabajar frente a la primera línea de los hospitales vivieron situaciones de lucha, alegría y superación.
\end{abstract}

Palabras clave: Prácticas; Enfermería; COVID-19; Clases remotas.

\title{
1. Introdução
}

A formação de um profissional é algo que necessita de uma capacitação e qualificação especifica, a qual parte de uma proposta educacional pautada no perfil do formando e seu campo de atuação. É nesta perspectiva que se apresenta o curso de enfermagem, sendo uma graduação que busca capacitar um profissional para atuar na intervenção de problemas e situações de doenças e saúde do ser humano (Santos, 2006).

$\mathrm{O}$ curso de bacharelado em enfermagem segue as orientações das Diretrizes Nacionais Curriculares do mencionado curso, apresentando que há a necessidade de compreensão e desenvolvimento de algumas competências básicas como atenção à saúde, comunicação, gestão e liderança, educação em saúde, desenvolvimento profissional, pesquisa, tomada de decisões e outras (Fernandes \& Rebouças, 2013).

Para o curso de enfermagem aponta-se que para que tais competências sejam desenvolvidas é necessário a utilização de aulas teóricas e práticas, que preparem o discente para a atuação em campo de trabalho, dessa forma, diversas são as disciplinas que promovem a capacitação desses profissionais, sendo o estágio curricular supervisionado, uma das mais importantes, pois prevê o contato direto com os diferentes serviços de saúde, aliado a teoria a pratica e evidenciando o exercício profissional em campo (Souza et al. 2020).

Frente a isso, o curso prevê a formação de um profissional que atua de maneira multiprofissional frente as necessidades do Sistema Único de Saúde. Quando se menciona a formação em saúde, logo remete-se a aulas presenciais e ao estágio, que permitem que o acadêmico tenha contato direto com a prática e com a teoria, já que ambas são fundamentais para a sua formação (Bezerra, 2020).

Todavia, em dezembro de 2019, tal cenário sofreu modificações, devido ao surgimento da doença COVID-19, houve a utilização de novos protocolos de segurança, que influenciaram no modo de vida e em diversas esferas da sociedade, dentre elas a educação, que precisou adequar suas aulas presenciais para o ensino remoto de acordo com as medidas de contenção tomadas, as quais tiveram seu início a partir de março de 2020 (Silva et al. 2020).

A saber, a doença COVID-19 é uma infecção respiratória provocada pelo Corona vírus da Síndrome Respiratória Aguda Grave 2 (SARS-CoV-2), o mesmo é disseminado de pessoa para pessoa através do contato com as gotículas de saliva, espirro ou tosse, pelo contato direto com boca, nariz e olhos, ou por intermédio de objetos contaminados. A doença surgiu em 2019 na cidade de Wuhan na China e se proliferou para todo mundo causando impactos significativos (Franzoi \& Cauduro, 2020)

Em fevereiro de 2020, o Brasil declara o estado de pandemia, iniciando em março medidas de quarentena em todo o 
território nacional, as quais ainda permanecem em sua maioria até os dias atuais. Tais medidas envolvem o distanciamento social para evitar aglomerações, fechamento de serviços não essenciais, adoção de medidas e protocolos de segurança como uso de máscara, lavagem de mãos, uso do álcool em gel, quarentena as pessoas com suspeitas, entre outas. (Silva et al. 2020)

Dentre os setores que sofreram alterações destaca-se a educação, que passou a adotar o ensino remoto como uma solução para a continuidade das aulas presenciais, já que houve o fechamento das instituições de ensino para a segurança de toda a população. Frente a isso, diversos debates sobre os impactos na formação dos profissionais surgiram, principalmente quanto aqueles que irão atuar na saúde, como o caso dos cursos de enfermagem (Bezerra, 2020).

Explica-se que, por meio da Portaria 343/2020, no Ministério da Educação, foi autorizado em caráter excepcional, a utilização das tecnologias como forma de mediar as aulas para os cursos na área de diversas áreas, inclusive da saúde, apontando para a necessidade de continuidade do processo de ensino. Em face a isso, diversas universidades, professores e discentes tiveram que se adaptar para a realização das aulas remotas (Brasil, 2020).

O ensino remoto emergencial constitui-se como uma alteração momentâneo, como alternativa para a continuidade da educação superior, sendo essa mediada pelas tecnologias de comunicação e informação (TIC). A mesma difere-se da educação a distância (EAD), pois as aulas são realizadas em um formato diferente, a partir da utilização de webconferência em plataformas digitais, de forma instantânea, a qual os alunos devem estar presentes conforme ocorria nas aulas presenciais (Franklin, Vasconcelos \& Eduardo, 2020)

O curso de enfermagem se encontra inserido no meio desse cenário contextualizado, o mesmo irá atuar na linha de frente no combate ao COVID-19. Contudo, questiona-se se tal adoção se torna benéfica para a formação de enfermeiros, mediante as especificidades de seu trabalho que carece de uma base teórica e prática para a formação de um profissional qualificado (Carneiro et al. 2021).

Com a urgência em qualificar os discentes dos cursos de enfermagem, fizeram com que as aulas em modalidade não presencial tornassem fundamental, porém vale contestar se a metodologia remota contribui para a formação dos indivíduos que irão atuar de maneira prática em face de inúmeros pacientes, bem como surgem questões referente ao estágio, no qual, os alunos com poucos conhecimentos e preparo são inseridos em hospitais lotados, com falta de recursos e materiais de proteção, vivenciado todos os dias mortes sem meios para auxiliar equipes e pacientes na luta contra o COVID-19 (Lira et al. 2020).

Diversos alunos descrevem as dificuldades dos estágios, os acadêmicos que estão vivenciando tal período relatam inúmeros problemas, medos, angustias e limitações. Esses relatos derivam principalmente da insegurança e da falta de preparo, pois ainda se encontram em período de formação, e com as aulas remotas o esclarecimento de dúvidas tornam-se mais complexos. Todavia, atuam na linha de frente a partir do princípio ético da profissão, auxiliando e prestando assistência a toda a população e ao sistema de saúde que se encontram em um esgotamento (Souza et al. 2020).

Diante do exposto, aponta-se que a presente pesquisa tem como objetivo evidenciar o contexto acadêmico referente ao estágio supervisionado do curso de Bacharelado em Enfermagem, durante o período pandêmico da COVID-19, revelando as dificuldades e limitações encontradas pelos discentes no campo de atuação.

\section{Referencial Teórico}

\subsection{A pandemia da Covid-19 e as mudanças na sociedade}

Dentro da sociedade atual, pode-se visualizar uma certa rotina entre as pessoas, os quais realizam diariamente ações corriqueiras e cotidianas, como deslocar-se para seus empregos ou estudos, passear em parques, encontrar amigos em bares, lanchonetes e shoppings, ir à academia, frequentar restaurantes, entre outras atividades que compõem uma estabilidade na vida humana (Bezerra et al. 2020). 
Essa estabilidade na rotina, é vista como algo comum e intrínseco ao ser humano que vive dentro da sociedade, a qual só é abalada mediante a alguma imprevisibilidade ou um acontecimento anormal. É mediante a essa premissa, que se aponta que o ano de 2019 e consequentemente os anos seguintes, marcou a história da humanidade, a qual se deparou com um novo vírus e uma nova doença que modificou a rotina de inúmeras pessoas, bem como demandou de uma nova adoção de atitudes (Malta et al. 2020).

Em dezembro de 2019, surge um novo vírus na China, na cidade de Wuhan, os primeiros casos a serem constatados tinham como similaridade a exposição a um mercado de frutos do mar da cidade, onde também se comercializava animais vivos. Tal doença apresentou um alto exponencial de transmissão, sendo necessário ao país em 31 de dezembro de 2019, noticiar a Organização Mundial da Saúde sobre o surto (Moretti, Guedes Neta \& Batista, 2020).

A nova doença passou a ser conhecida como COVID-19, a qual era ocasionada pela transmissão do vírus SARS-CoV2, a mesma apresenta uma alta transmissibilidade, dando seu contágio por meio, do contanto com gotículas contaminadas de secreções da orofaringe, bem como de superfícies e objetos contaminados onde o vírus pode permanecer por até 72 horas (Aquino et al. 2020).

A alta transmissibilidade e o desconhecimento sobre essa nova doença, resultaram em uma crise sanitária global, onde foi decretado no dia 11 de março de 2020 pela OMS uma pandemia mundial, na qual mais de 210 países e territórios já haviam notificados casos de pessoas infectadas (OMS, 2021).

A COVID-19 é uma doença infecciosa, que causa problemas principalmente nas vias respiratórias, a mesma pode apresentar sintomas leves e moderados como febre, tosse seca, cansaço, perda de paladar e/ou olfato, dor de cabeça, e em alguns casos pode resultar em sintomas mais graves como falta de ar, dores no peito, perda da fala e do movimento (Padilha, 2020).

Tais sintomas podem aparecer entre 5 a 14 dias, o que auxilia na transmissão da doença, já que o tempo de surgir os sintomas, faz com que muitos não se isolem vivenciando sua rotina normalmente e contribuindo assim para a transmissão. A COVID-19 apresenta como grupo de riscos os idosos e pessoas com comorbidades, o que resulta na maioria das vezes na necessidade de hospitalização para cuidados intensivos e uso de ventiladores mecânicos, podendo acarretar na morte desses pacientes (Iser et al. 2020).

O primeiro caso registrado da américa Latina, ocorreu no Brasil no estado de São Paulo, no dia 25 de fevereiro de 2020, onde um homem de 61 anos tinha retornado de uma viagem à Itália apresentando os sintomas, o mesmo foi atendido e permaneceu em isolamento domiciliar, porém isto não impediu que o vírus se expandisse rapidamente (Peixoto et al. 2020).

Atualmente o Brasil apresenta um total de 14 milhões de casos notificados, sendo desses 35 mil mortos, e apesar do início das campanhas de vacinação da vacina contra o COVID-19, os números de casos crescem diariamente, ocorrendo mais de 1000 mortes por dia, e esgotando os recursos e superlotando as unidades hospitalares de todo o território nacional. (Ministério da saúde, 2021)

Frente a todo esse cenário drástico, diversos representantes do mundo inteiro se mobilizaram para adotar medidas de contenção da transmissão, bem como do cuidado aos indivíduos infectados, onde visualiza-se a criação de protocolos de segurança e a adoção de novos comportamentos entre a população. Como esclarece Moretti, Guedes Neta e Batista (2020, p.2):

A OMS recomendou aos governos a adoção de intervenções não farmacológicas (INF), as quais incluem medidas de alcance individual (lavagem das mãos, uso de máscaras e restrição social), ambiental (limpeza rotineira de ambientes e superfícies) e comunitário (restrição ou proibição ao funcionamento de escolas e universidades, locais de convívio comunitário, transporte público, além de outros espaços onde pode haver aglomeração de pessoas). 
Salienta-se que frente a esse cenário e a instauração da lei ${ }^{\circ} 13.979 / 2020$, que dispõe sobre as medidas de enfrentamento da COVID-19 no Brasil, diversas mudanças surgiram no cotidiano da sociedade mundial, no Brasil o distanciamento social modificou a modo que ocorrem as relações interpessoais, entre outros setores como o trabalho e o emprego (Peixoto et al. 2020).

O uso de máscara e as restrições de convivência, modificaram o modo como o ser humano se relaciona, atualmente as conversas e encontros digitais mediam as relações entre a sociedade. Em adição, a utilização dos protocolos de segurança a saúde, como higienização das mãos, cuidados com alimentação, evitar aglomerações, entre outras ações fizeram com que as sociedades criassem novos hábitos com o intuito de se proteger. (Padilha, 2020)

É importante esclarecer ainda sobre a maior mudança na rotina diária de inúmeros brasileiros, como aponta Moretti, Guedes Neta e Batista (2020, p.33):

Sem aviso prévio, a forma de estudar, trabalhar e viver foi alterada e, muitos contratos não foram cumpridos ou tiveram que ser modificados. Além disso, esse novo modo de viver trouxe à tona a importância de levarmos em consideração a realidade de cada um, principalmente quando consideramos as questões de trabalho nos delineamentos de home office ou de estudo homeschooling. Outros trabalhadores perderam o seu emprego.

Devido ao distanciamento social muitos trabalhadores tiverem que se ausentar presencialmente de seus serviços, realizando-os de forma remota dentro de seus lares. Do mesmo modo, ocorreu com a questão no ensino dentro do país, onde escolas e instituições de ensino foram fechadas, adotando o ensino remoto a partir do uso das tecnologias de informação e comunicação, o qual será discutido na próxima seção.

\subsection{O ensino remoto no curso de bacharelado em enfermagem}

$\mathrm{Na}$ seção anterior foram abordadas as principais mudanças que ocorreram devido as decisões governamentais para a contenção do vírus, o que refletiram dentro da sociedade como uma nova forma de observar o mundo, desenvolvendo novas atitudes e comportamentos frente a crise sanitária global.

A respeito das medidas estimuladas pelos governantes brasileiros, recorda-se de maneira sintetizada suas ações:

As principais estratégias estabelecidas pela OMS foram: interromper a transmissão de humano para humano, identificar, isolar e cuidar dos pacientes infectados., acelerar o desenvolvimento de diagnósticos, terapêuticas e vacinas., realizar atividades de conscientização da comunidade., e minimizar os impactos sociais e econômicos (Lira et al. 2020, p.2).

Dentre as maiores consequências acarretadas pela pandemia da COVID-19, tem-se as mudanças dentro do setor educacional, devido os protocolos de segurança que visam o distanciamento social, escolas de mais de 190 países foram fechadas no sentido de evitar aglomerações e preservar a saúde dos alunos, docentes e demais agentes envolvidos com o espaço escolar (Bastos et al. 2020).

O fechamento da escola se deu em todas as etapas de ensino desde a educação infantil até o ensino superior, onde propôs-se novas formas de promover o processo de ensino e aprendizagem tornando-se um desafio tanto para gestores e professores como para os alunos que tiveram que se readequar (Carneiro et al. 2021).

Em um primeiro momento diante da crise mundial, diversas instituições de ensino optaram pela suspensão das aulas e cancelamento do calendário acadêmico até que o cenário fosse estabilizado. Entretanto, visualizou-se a piora da realidade frente a pandemia, onde os números de infectados e mortos cresceram de maneira drástica (Bezerra, 2020). 
Frente a essa questão, foi necessária a mobilização do governo e das instituições de ensino na busca de medidas que proporcionassem a continuidade do ensino, como solução foi instaurado o ensino a partir da mediação das tecnologias de informação e comunicação - TIC (Oster et al. 2020).

De antemão esclarece que as tecnologias de informação e comunicação, denominadas pela sigla TIC, consistem em um "conjunto de recursos tecnológicos, utilizados de forma integrada, com um objetivo comum" (Oster et al. 2020). Nesta perspectiva, aponta-se que como forma de promover a continuidade do ensino principalmente no ensino superior iniciou-se um processo de mediação da aprendizagem por meio das plataformas digitais (Bezerra, 2020).

A utilização das TIC consiste em uma adaptação de uma tendência comum dentro da sociedade atual, como explora Lira et al (2020, p.2):

No entanto, as tendências educativas do século XXI estão marcadas pela integração científica e tecnológica, que permitem a gestão acadêmica de todos os atores, assistidos por TICs. Essas estratégias de desenvolvimento e perspectivas acadêmicas são geradas fundamentalmente por plataformas digitais, tecnologias e métodos baseados em um cenário educativo com novas condições para a autoaprendizagem mediadas pelos ambientes virtuais.

Todavia é válido apresentar que o ensino mediado pelas TIC no período da pandemia deve ser visualizado de maneira diferenciada ao modelo educacional conhecido como educação à distância - EAD, pois a proposta formulada para tal momento apresenta como principal diferença a presença em tempo real dos alunos e professores nas plataformas digitais (Carneiro et al. 2021).

Sobre essa questão explica-se que o modelo adotado no período da pandemia de educação é compreendido a partir do ensino remoto, sendo esse configurado em dois moldes: o emergencial e o intencional. O ensino remoto emergencial configura-se como uma mudança temporária, sendo utilizada frente a situações de crise e catástrofes, como no caso da pandemia COVID-19 (Silva et al. 2020).

A proposta do ensino remoto emergencial é a continuidade do ensino de modo que haja menos perda no processo de aprendizagem, tornando-se uma opção temporária até que tudo volte à normalidade. Dessa forma, não há mudanças entre professores, planejamento do conteúdo ou organização das turmas, o ensino continua o mesmo apenas modificação a questão da presença e do uso da tecnologia como forma de transmissão do conhecimento (Silva et al. 2020).

No que tange, o ensino remoto intencional, Lira et al (2020, p.4) expõe:

[...] o corpo de professores, a equipe pedagógica e os gestores pensam, elaboram essa modalidade. Tem a intencionalidade de aprendizagem e não simplesmente a entrega de conteúdos ou entrega de aulas para ter a efetividade dessa aprendizagem. Há um processo organizacional desse ensino. As estratégias são centradas na aprendizagem.

Entretanto, questiona-se qual a diferença dessas modalidades frente a educação a distância. Destaca-se que o ensino remoto não é EAD, pois tal método implica em uma estrutura onde os conteúdos são feitos sob encomenda e avaliados por tutores, as aulas não são feitas de maneira sincrônicas, e sim são gravadas e dispostas aos alunos, que procuram os tutores em caso de dúvidas (Lima et al. 2020).

A mesma segue uma estrutura padronizada com material didático e aulas disponibilizadas de maneira assincrônica, onde atividades e avaliações são produzidos e corrigidos a partir de critérios em grande escala. O aluno dessa forma, não tem contato direto com o professor, apenas com seus tutores que realizam o esclarecimento de dúvidas, correções e explicação de trabalhos (Silva et al. 2020).

Diante disso, adentra-se na questão do curso de enfermagem e a adoção do ensino remoto como possibilidade de promover a continuidade da formação profissional e acadêmica. A partir da Portaria $\mathrm{n}^{\circ}$ 544, de 16 de junho de 2020, foi 
instaurada a possibilidade dos cursos de formação superior adotar o ensino remoto e à distância como forma de proporcionar um meio para a prática de ensino (Brasil, 2020).

Dentro do curso de enfermagem, a questão quanto a adoção do ensino a distância sofreu inúmeras críticas, devido ao perfil do profissional formado, conforme as premissas levantadas apontam-se que os cursos na área da saúde, necessitam de uma responsabilidade frente a formação dos profissionais, que carecem de uma interação presencial para o desenvolvimento de competências necessárias para a sua atuação no Sistema Único de Saúde (Silva et al. 2020).

Conforme esclarece o COFEN, a enfermagem é uma profissão onde a prática demanda dos processos de aprendizagens advindos das relações interpessoais, onde por meio da inserção nos espaços formais e informais o profissional desenvolve suas especialidades (Bezerra, 2020). Carneiro et al (2021, p.8672) cita que "[...] para o exercício profissional na assistência, qualquer deslize impulsionado pela falta de manejo interpessoal pode representar danos irreparáveis".

Apesar das críticas mencionadas nota-se a existência de cursos de enfermagem em que utiliza o modelo de Educação à distância, apresentando apenas os estágios e atividades práticas em laboratórios devem ser realizados de forma presencial, como forma de possibilitar o contato e a aprendizagem com o campo de atuação (Lima et al. 2020).

Sobre tal questão Lira et al (2020, p.4) esclarece:

Destaca-se que, por meio das Portarias n. 343 (17 de março de 2020) e 345 (19 de março de 2020), ocorreu a vedação de substituição de atividades práticas, atividades profissionais, de estágios e laboratórios por aulas que utilizam TIC. Porém, tais dispositivos legais foram revogados e substituídos pela Portaria n. 544, de 16 de junho de 2020. A nova portaria autoriza, em caráter excepcional, a substituição das aulas presenciais por aulas que utilizam TIC até 31 de dezembro de 2020. Além disso, flexibiliza a possibilidade de atividades práticas e estágios não presenciais, desde que obedeçam às Diretrizes Curriculares Nacionais dos respectivos cursos.

É nesta questão, que diversos autores criticam o processo de ensino e aprendizagem, pois evidenciam que a utilização das tecnologias dentro do curso de enfermagem deve ser encarada como um complemento do trabalho realizado dentro da sala de aula, permitindo assim um novo olhar sobre o conhecimento a ser construído (Bezerra, 2020).

Sobre essa questão, o curso de bacharelado em enfermagem deve-se pautar no desenvolvimento de novas habilidades técnicas, onde traga a formação de um caráter informacional, técnico e procedimental. Essas habilidades devem permitir a formação de um profissional que possa prover um atendimento humanizado, desenvolvendo competências como a criticidade, a reflexão e a autonomia (Carneiro et al. 2021).

Conforme Lira et al (2020, p.3):

A formação para o SUS deve pautar-se nas necessidades de saúde das pessoas e, para tanto, requer uma formação interprofissional, humanista, técnica e de ordem prática presencial, permeada por essa integração ensino-serviçocomunidade, experienciando a diversidade de cenários e espaços de vivências e práticas, que estará impedida e comprometida na modalidade EAD.

Entretanto apesar de tais críticas, a necessidade frente a pandemia, viabilizou a utilização do ensino remoto como forma de continuar o processo de formação desses profissionais, principalmente devido a sua urgência de formação para a atuação em campo, onde os profissionais tornaram-se essenciais para o atendimento aos pacientes infectados (Oster et al. 2020).

Tais profissionais irão atuar na linha de frente ao combate contra a COVID-19, necessitando estar preparado para as diversas demandas. Isso gera uma insegurança aos discentes e docentes, que além de adaptar-se ao novo cenário educacional, devem promover um formação e acompanhamento aos estudantes que irão para as unidades de saúde, realizar seus estágios, e ajudando a equipe hospitalar (Lima et al. 2020). 
Aliada a essa questão da necessidade de tal profissional em campo, verifica-se que foi promulgada a Portaria n 374 de 03 de abril de 2020, que autoriza a colação de grau antecipada dos alunos que cumpriram $75 \%$ da carga horária do estágio supervisionado para os cursos de Enfermagem, Medicina, Farmácia e Fisioterapia, justificando a necessidade de urgência de tais profissionais para o enfretamento da crise sanitária global que tem levado a saúde pública ao esgotamento (Brasil, 2020).

Sobre a adoção do ensino remoto para o curso de enfermagem em regime emergencial, esclarece que o mesmo apresenta pontos positivos destacados no âmbito da pesquisa, onde se promove que futuramente possa realizar um aproveitamento das tecnologias aliadas ao ensino, como forma de ampliar as possibilidades em sala de aula (Oster et al. 2020).

Dentre os pontos positivos se destaca o acesso a uma gama de informações disponíveis por meio das TIC, para o aluno é oportunizado o contato com diversos conhecimentos, possibilitando a cooperação, o esclarecimento de dúvidas e a busca por novas pesquisas do ramo. Além disso, o aluno apresenta o desenvolvimento de uma nova competência, a da organização tanto do espaço, como de sua rotina (Carneiro et al. 2020).

Em suma, o ensino remoto no curso de enfermagem, instaurou diversas visões sobre o modo de ensinar, passou a ser visto como uma solução temporária para promover a continuidade do ensino, sendo complementado pelo estágio supervisionado que permite o desenvolvimento das habilidades necessárias para tal profissional (Lima et al. 2020).

É nessa perspectiva, que surge novas questões, principalmente quanto as fragilidades na formação obtida por meio do ensino remoto, aliadas ao medo e insegurança dos discentes frente o enfrentamento da pandemia (Lira et al. 2020).

\subsection{O estágio em enfermagem durante a pandemia Covid-19}

Como já apresentando nesse estudo o processo de formação do enfermeiro modificou-se, a adoção do ensino remoto trouxe uma nova visão ao processo de ensino e aprendizagem. Além dessas mudanças no ensino, é válido expor que as mesmas se estenderam a questão do estágio supervisionado do curso.

O estágio é um momento de aprendizagem, onde o futuro profissional da enfermagem adentra no campo de atuação, vivenciando o cotidiano da profissão por meio de desafios, possibilidades, problemáticas e limitações. Em adição, é importante ressaltar que o estágio é o espaço de inter-relação entre a teoria e a prática, onde o aluno pode aplicar em situações reais os conhecimentos e competências obtidos durante as disciplinas teóricas (Ribeiro, Martins \& Dalri, 2020).

A prática do estágio supervisionado é algo fundamental para a formação profissional e acadêmica, por isso o mesmo apresenta um caráter obrigatório como requisito para a conclusão do curso de bacharelado em enfermagem (Franklin, Vasconcelos \& Eduardo, 2020).

Como exibe as Diretrizes Curriculares Nacionais do Curso de Graduação em Enfermagem:

[...] é de suma importância a inserção do discente em diferentes cenários de prática profissional, com intuito de prover a formação de enfermeiros pautada no desenvolvimento de competências e habilidades generalistas, humanistas, críticas e reflexivas, tornando-os aptos a identificar e intervirmos problemas de saúde/doença mais prevalentes no perfil epidemiológico do país (Franklin, Vasconcelos \& Eduardo, 2020, p. 71298)

Acerca do estágio, esclarece que pode ocorrer em duas modalidades, o primeiro sob um caráter obrigatório, apresentado como um componente curricular, com carga horária especifica, voltada para a conclusão do curso, sendo esse o estagiário supervisionado por um docente (Souza et al. 2020).

Por sua vez, há o estágio em caráter não obrigatório, o qual é opcional, na maioria das vezes com alguma remuneração, onde o estagiário é acompanhado por um supervisor da unidade onde trabalha, no caso da enfermagem por um enfermeiro. Ambos os estágios apresentam contribuições positivas para a formação acadêmica, pois permitem que o discente 
adentre no mercado de trabalho e consiga desenvolver as ações ocupacionais sob a supervisão de um profissional que irá auxilia-lo e proporcionar a troca de ideias (Brasil et al. 2020).

Diante dessa apresentação, é válido expor que em face a pandemia COVID-19, a realização do estágio obrigatório passou a ser optativa, sendo possível que o acadêmico possa realizá-lo posteriormente quando o campo da saúde se normalize. (Simões et al. 2020). Porém, inúmeras questões foram levantadas sobre o estágio de enfermagem em tempos de pandemia, principalmente devido a urgente demanda desse profissional dentro das unidades hospitalares (Bezerra, 2020).

Inúmeros estudantes frente a tal necessidade propuseram-se a realizar atividades de modo a contribuir com a realidade brasileira, conforme Souza et al (2020, p.4) salienta:

A decisão de permanecer no $\operatorname{ECS}^{1}$ foi devido a que as mesmas consideraram essa atividade como um compromisso social junto à força de trabalho da $\mathrm{ESF}^{2} \mathrm{e}$ da sociedade, em um momento em que é necessário intensificar o combate a COVID-19. A conduta das estudantes vai ao encontro do que se espera na formação do enfermeiro, que seja pautada em princípios éticos, com senso de responsabilidade social e no compromisso com a cidadania.

Além disso, a optativa pelo estágio não obrigatório também ocorreu diante da campanha realizada pelo Governo Federal, por meio do Programa "O Brasil Conta Comigo" iniciado em abril de 2020, a proposta em edital consiste em uma chamada pública a todos os estudantes do ensino superior que cursam graduações na área da saúde, propondo que esses integrassem de maneira voluntária a rede pública de saúde, realizando uma carga horaria de 40 horas semanais sob a supervisão dos profissionais da instituição em que irão estagiar (Brasil et al. 2020).

O intuito principal de tal programa é o fortalecimento do Sistema Único de Saúde, que diante das demandas da pandemia, o qual está entrando em colapso, devido a superlotação e o esgotamento dos profissionais. Dessa forma, os discentes voluntários atuariam em diversos níveis de atenção, dando um suporte aos trabalhadores da rede pública de saúde (Souza et al. 2020).

É visível a participação de inúmeros estudantes que assumem o dever e o caráter ético da profissão visando o enfrentamento da crise sanitária global. Entretanto é importante ressaltar seus anseios diante desse momento e da realização tanto do estágio obrigatório como o não obrigatório (Simões et al. 2020).

Os principais pontos destacados pelos estudantes condizem com as inseguranças frente a doença, a incerteza do contagio, bem como a possibilidade de transmissão é uma das problemáticas mencionadas. O medo frente a doença provoca a ansiedade desses profissionais, que temem por sua saúde assim como dos seus familiares (Franklin, Vasconcelos \& Eduardo, 2020).

É importante esclarecer que os mesmos podem desistir do estágio, porém dentro das leituras realizadas apontou-se que o dever ético e cívico, frente a pandemia, fez com que tais profissionais permanecem ajudando o próximo, apenas modificando suas rotinas de modo a proteger as relações interpessoais (Souza et al. 2020).

O segundo ponto destacado acerca dos problemas encontrados é a insegurança quanto a sua capacidade de atuação, devido a não conclusão do curso aliado as mudanças para o ensino remoto, muitos estagiários de enfermagem relatam o despreparo para atuar dentro desse cenário. Cabe salientar que em face a essa questão, os supervisores do estágio devem realizar o aconselhamento e o acompanhamento direto, instruindo os mesmos, de modo que esses possam desenvolver suas habilidades (Ramos et al. 2020).

\footnotetext{
${ }^{1}$ No artigo "Estágio curricular supervisionado em enfermagem durante a pandemia de Coronavírus: experiências na atenção básica" de Souza et al (2020) a sigla ECS refere-se a Estágio Curricular Supervisionado.

${ }^{2}$ No artigo "Estágio curricular supervisionado em enfermagem durante a pandemia de Coronavírus: experiências na atenção básica" de Souza et al (2020) a sigla ESF refere-se Estratégia Saúde da Família.
} 
Complementarmente outra problemática acerca do estágio condiz com a questão da falta de equipamentos e o esgotamento do sistema de saúde, a alta procura pelos Equipamentos de Proteção individual acarretou em um superfaturamento, bem como a falta de materiais para a produção dos mesmos. Isto dificulta a atuação do enfermeiro, que assume uma posição de perigo, sendo necessário a suspensão do estágio (Brasil et al. 2020).

Outro problema é apresentado por Souza et al (2020, p.5-6):

Atuar na linha de frente de um agente invisível é um momento de preocupações, de pressão psicológica e que pode ocasionar problemas mentais aos estudantes, decorrentes do medo, angústias e ansiedades. As estratégias utilizadas pelas estudantes para lidar com as questões emocionais pelo risco de contaminação e morte foi garantida por meio vínculo e diálogo aberto com os enfermeiros preceptores e com os professores supervisores, na qual elas tinham liberdade de expressar os sentimentos e angústias bem como, de expressar sobre o desejo de suspender o ECS.

Por fim, relata uma última questão apontada pelas leituras acerca do estágio em enfermagem em tempos de pandemia, os relatos quanto a problemática da disseminação das fake News e o negacionismo de alguns cidadãos (Brasil et al. 2020). Mediante ao trabalho de orientação e esclarecimento, diversos estagiários relataram a dificuldade de conversar com alguns indivíduos sobre a importância da higienização, uso de máscaras e cuidados, os quais utilizavam de maneira incorreta, ou até mesmo se negavam a utilizar máscaras e manter o distanciamento (Brasil et al. 2020).

No que tange as dificuldades dos alunos frente as aulas remotas relacionadas ao estágio supervisionado são interessantes esclarecer que as leituras apresentam que os problemas enfrentados residem em dificuldades de acesso as plataformas e materiais devido à falta de capacitação, familiaridade com o sistema, e até questões econômicas, como não possuir computadores ou uma internet adequada (Bastos et al. 2020).

Além disso, acrescenta os problemas relativos a concentração e falta de um espaço adequado para estudo, que acaba por dispersar os discentes que ainda estão em um processo de adaptação as novas mudanças. Revelam ainda que com as disciplinas relativas ao estágio, sentem falta do contato direto com o professor que auxilia no manuseio e possibilita a experimentação dentro da sala de aula de situações vivenciadas no estágio, as quais são limitadas diante das aulas remotas com cada um em seu lar (Bastos et al. 2020).

Entretanto, é importante salientar que apesar das dificuldades enfrentadas durante a realização do estágio em tempos de pandemia, o mesmo proporciona experiências únicas, bem como promove novos conhecimentos e habilidades no futuro enfermeiro (Ramos et al. 2020).

Um dos pontos destacados é a questão da superação frente as inseguranças, estudantes relatam que sentem medo de adentrar no campo de atuação, não se sentindo preparados para atuar, como visto essa questão também foi intensificada frente ao ensino remoto (Ramos et al. 2020). Porém, é fundamental ressaltar que diante do contexto atual e da movimentação constante, há uma superação dessas fragilidades, promovendo uma maior autonomia e segurança para os discentes atuantes (Souza et al. 2020).

Outro aspecto condiz com a vivencia de uma realidade única, a relação entre o trabalho e a pandemia é algo estudado em livros, como apresenta Brasil et al (2020, p.5):

A participação acadêmica em período de pandemia, em forma de estágio extracurricular, permitiu a cada profissional em formação, não apenas vislumbrar uma possível situação, antes vista apenas em bibliografias históricas, mas atuar de forma ativa no combate ao novo coronavírus e suas eventuais consequências, fortalecendo a base de conhecimento dos envolvidos ainda durante a formação.

Diante disso, fica evidente que o estágio traz novas experiências para o discente que aprimora seus conhecimentos e prática, percebe-se que mesmo diante do cenário pandêmico vivenciado, o qual a insegurança e o medo fazem parte da 
realidade dos estudantes que realizam o estágio, proporciona diversos aspectos positivos, promovendo a formação ética, humanizada e completa de tais profissionais (Souza et al. 2020).

\section{Materiais e Métodos}

A presente pesquisa trata-se de um estudo bibliográfico centrado na revisão literária baseada em produções cientificas nacionais sobre a temática. Tal pesquisa centra-se em um estudo qualitativo e exploratório acerca dos desafios enfrentados pelos discentes do curso de bacharelado em enfermagem diante da realização do estágio supervisionado durante a pandemia da COVID-19.

O levantamento de dados foi realizado a partir de estudos científicos como artigos, capítulos de livros e legislação sobre a temática apresentada. Foram selecionados por meio de critérios como apresentação em língua portuguesa e período entre 2020 e 2021.

A pesquisa foi realizada em repositórios acadêmicos e sites como Scientific Eletronic Library online (SCIELO) e Google Acadêmico. Para a seleção das fontes foram utilizadas palavras-chave como enfermagem, estágio supervisionado, aulas remotas, dificuldades do estudante de enfermagem.

Ao todo foram selecionados 29 estudos que apresentam informações relevantes para a discussão, a tabulação dos mesmos ocorreu por meio do fichamento em forma de tabela indicando título, autores, objetivos, ano e cidade de publicação.

\section{Resultados e Discussão}

O presente estudo buscou a abordagem da temática acerca dos desafios e dificuldades enfrentados pelos discentes do curso de bacharelado em enfermagem frente a realização do estágio supervisionado durante a pandemia COVID-19. No quadro a seguir são apresentados os principais estudos utilizados para a construção da pesquisa:

Quando 1 - Principais estudos utilizados no desenvolvimento do trabalho.

\begin{tabular}{|c|c|c|c|c|}
\hline Título & Autor & Ano & $\begin{array}{l}\text { Cidade de } \\
\text { publicação }\end{array}$ & Objetivo \\
\hline $\begin{array}{l}\text { Medidas de distanciamento social } \\
\text { no controle da pandemia de } \\
\text { COVID-19: potenciais impactos e } \\
\text { desafios no Brasil }\end{array}$ & Aquino et al. & 2020 & Salvador & $\begin{array}{c}\text { Sistematizar as evidências sobre o impacto das } \\
\text { medidas de distanciamento social na epidemia de } \\
\text { COVID-19 e discutir sua implementação no } \\
\text { Brasil. }\end{array}$ \\
\hline $\begin{array}{l}\text { Estado da arte sobre o ensino de } \\
\text { enfermagem e os desafios do uso } \\
\text { de tecnologias remotas em época } \\
\text { de pandemia do corona vírus }\end{array}$ & $\begin{array}{c}\text { Italla Maria } \\
\text { Pinheiro Bezerra }\end{array}$ & 2020 & $\mathrm{~s} / 1$ & $\begin{array}{l}\text { Descrever o estado da arte sobre o ensino de } \\
\text { enfermagem e os desafios do uso de tecnologias } \\
\text { remotas em época de pandemia do Corona vírus. }\end{array}$ \\
\hline $\begin{array}{l}\text { O ensino de enfermagem e os } \\
\text { desafios do uso de tecnologias } \\
\text { remotas em tempos de pandemia do } \\
\text { coronavírus (covid-19) }\end{array}$ & Carneiro et al. & 2021 & Curitiba & $\begin{array}{c}\text { Refletir sobre a formação do enfermeiro e os } \\
\text { desafios para o uso de tecnologias remotas no } \\
\text { contexto da pandemia provocada pelo novo } \\
\text { coronavírus (COVID-19). }\end{array}$ \\
\hline $\begin{array}{c}\text { Educação em enfermagem: } \\
\text { desafios e perspectivas em tempos } \\
\text { da pandemia COVID-19 } \\
\end{array}$ & Lira et al. & 2020 & Brasilia & $\begin{array}{c}\text { Discutir sobre os desafios e perspectivas da } \\
\text { educação em enfermagem em tempos da } \\
\text { pandemia COVID-19 }\end{array}$ \\
\hline $\begin{array}{l}\text { Contribuições do estágio não } \\
\text { obrigatório para a formação do } \\
\text { enfermeiro em meio à pandemia do } \\
\text { novo coronavírus (covid-19): um } \\
\text { relato de experiência }\end{array}$ & $\begin{array}{l}\text { Thainara Araújo } \\
\text { Franklin, Caroliny } \\
\text { de Oliveira } \\
\text { Vasconcelos, Pedro } \\
\text { do Nascimento } \\
\text { Eduardo }\end{array}$ & 2020 & Curitiba & $\begin{array}{l}\text { Relatar as contribuições do estágio não } \\
\text { obrigatório no setor da vigilância epidemiológica } \\
\text { para a formação do enfermeiro em meio à } \\
\text { pandemia do novo coronavírus (covid-19) }\end{array}$ \\
\hline $\begin{array}{l}\text { Estágio curricular supervisionado } \\
\text { em enfermagem durante a } \\
\text { pandemia de coronavírus: } \\
\text { experiências na atenção básica }\end{array}$ & Souza et al. & 2020 & $\mathrm{~s} / 1$ & $\begin{array}{l}\text { Relatar as experiências de estudantes de } \\
\text { enfermagem durante o estágio curricular } \\
\text { supervisionado na atenção básica no cenário da } \\
\text { pandemia de coronavírus. }\end{array}$ \\
\hline
\end{tabular}


Fonte: Autores.

Aquino et al (2020) apresentam em seu estudo um panorama geral sobre o cenário vivenciado por toda a sociedade diante da pandemia COVID-19, o mesmo trouxe como principal contribuição para a pesquisa, a contextualização sobre as mudanças e as medidas de proteção adotadas nesse momento. A partir de sua revisão narrativa foi destacado a realidade brasileira e as modificações na rotina e das atividades diárias como a adoção do ensino remoto e do trabalho home office.

Bezerra (2020) por meio de sua sistematização das fontes secundárias da literatura sobre o tema evidenciou o ensino remoto voltado para o ensino superior, focalizando sua visão aos cursos de enfermagem. Ao abordar tais questões a mesma oportunizou a compreensão sobre as diferenças entre o ensino remoto e a educação a distância, revelando principalmente as dificuldades dos alunos frente ao novo modelo de ensino.

Sobre essa questão é interessante destacar que ao longo da pesquisa foi possível visualizar que as dificuldades enfrentadas pelos discentes do curso de bacharelado em enfermagem não reside apenas na realização do estágio, mas sim que essas se iniciam no momento das aulas, onde diversos problemas surgem denunciando principalmente uma desigualdade social e econômica da população brasileira (Bezerra, 2020).

A autora ainda apresenta que, tais problemas refletem principalmente na dificuldade de acesso, pois muitos não apresentam os recursos necessários devido a questões financeiras, bem como, há também a falta de conhecimento sobre as plataformas utilizadas, as quais eram desconhecidas por muitos. Em adição, há as inseguranças frente a transição de um curso presencial para um curso remoto, onde os alunos relatam falta de estimulo, dificuldades de concentração e atenção as aulas.

Aliada a essas questões, Carneiro et al (2021) apresentam alguns pontos positivos do ensino remoto para os discentes, como a ampliação das informações e meios de acesso, a construção de uma cultura digital, atualização tecnológica, facilidade de acesso independentemente do espaço geográfico, dinamicidade das aulas e horários e continuidade da relação professor/aluno mesmo diante da distância presencial.

Do mesmo modo, Carneiro et al (2021) faz uma articulação também dos pontos positivos acerca do ensino remoto reiterando as falas de Bezerra (2020) quando mencionam que os problemas frente as tecnologias digitais residem principalmente na falta de contato e conhecimento das ferramentas e plataformas, e que tais problemas não são visualizados apenas nos discentes, mas relatados por muitos docentes que precisaram se reinventar e adaptar suas aulas.

Em consonância a essa visão traz os estudos científicos de Lira et al (2020) o qual aborda de maneira mais incisiva os problemas e dificuldades enfrentados pelos discentes durante a pandemia, esclarecendo pontos como a legalidade da adoção do ensino remoto para o curso de enfermagem. Tais autores descrever que por meio do Medida Provisória $\mathrm{n}^{\circ}$ 934/2020, que dispõe sobre as aulas durante o período da pandemia do COVID-19, foi possível uma flexibilização das aulas presenciais do curso de enfermagem sendo adotado as aulas remotas mediadas pelas TIC.

Nesta perspectiva é interessante ressaltar que Lira et al (2020) vai além de apresentar as dificuldades das aulas remotas, mas traz um panorama sobre as possibilidades que a mesma oportunizou. Dessa forma, se destaca a possibilidade posterior:

As possibilidades para o período denominado pós-pandemia são muitas. Nestes tempos, novos formatos e artefatos para o ensino serão aplicados. E assim, acredita-se que para o retorno às atividades será necessário Ressignificar, Remodelar, Reconfigurar os planos de ensino (Os três R).

Um aspecto necessário é a ampliação dos eixos estruturantes para o processo ensino e aprendizagem. Se antes da pandemia predominavam os eixos epistemológicos, pedagógicos e metodológicos, no pós-pandemia ter-se-á que incorporar com mais densidade os eixos epidemiológicos, tecnológicos e psicológicos (Lira et al. 2020, p.4). 
Franklin, Vasconcelos e Eduardo (2020) apontaram a partir do seu estudo, o qual acompanharam dois estudantes de enfermagem durante a realização do estágio, os desafios enfrentados pelos alunos frente a pandemia COVID-19. Um primeiro ponto destacado pelos autores condiz com a questão que a realização do estágio passou a ser optativa, na qual os alunos poderiam escolher pela realização posterior das atividades após a volta da normalidade.

Todavia, como relata Franklin, Vasconcelos e Eduardo (2020) muitos discentes do curso de enfermagem assumiram a responsabilidade ética e profissional da futura profissão, adentrando ao sistema de saúde em colapso, como uma forma de auxiliar diretamente a linha de frente da pandemia. Os mencionados autores revelam principalmente os pontos positivos para a formação acadêmica e profissional dos discentes que se propuseram a realizar as atividades referente ao estágio seja ele o obrigatório ou não obrigatório.

Sobre os ganhos da realização do estágio neste cenário, revela-se que ao enfrentar um contexto apenas observados em livros e trabalhos científicos, os discentes vivenciam na prática questões relativas ao trabalho frente uma pandemia, constroem novos conhecimentos e metodologias para seu atendimento, bem como promovem novas habilidades como a articulação do tempo, recursos, prestação de socorro, e outros. (Franklin, Vasconcelos \& Eduardo, 2020).

Por fim, Souza et al (2020) focaliza suas considerações acerca dos problemas e dificuldades enfrentadas pelos discentes que estão estagiando na linha de frente contra a COVID-19, sobre isso elucidam:

[...] demonstraram sentimentos como o medo de serem contaminadas pela COVID-19 e as incertezas de uma possível evolução da doença. Esses sentimentos foram reforçados pelas atualizações constantes da mídia no que tange ao número de óbitos na população. O excesso de informações gera angústias e ansiedade, que repercutiram na atuação das estudantes. Os dados que evidenciam o adoecimento dos profissionais aumentam constantemente. Atuar na linha de frente de um agente invisível é um momento de preocupações, de pressão psicológica e que pode ocasionar problemas mentais aos estudantes, decorrentes do medo, angústias e ansiedades. (Souza et al. 2020, p.5)

Ainda em face aos desafios relatados no estudo de Souza et al (2020) apresentou-se o medo de contaminar os familiares durante o trabalho nos hospitais e unidades de saúde, onde diversos estudantes relataram afastar-se temporariamente dos familiares, realizando o contato apenas por meios das redes sociais, ligações e chamada de vídeo. Há também relatos quanto aos problemas relativos aos hospitais e recursos disponíveis, como a falta do equipamento individual de proteção, a lotação dos leitos e a falta de infraestrutura para atender a alta demanda de pacientes, o que provocou nos discentes uma angustia por não visualizar alternativas.

Ainda destaca a questão do descredito de parte da população, que ao procurar o sistema de saúde, negava-se a utilização de máscara e das medidas de segurança, colocando em risco a vida não apenas dos funcionários, mas de todos no local. Tal descredito é visualizado mediante as fake News enfrentadas de forma direta pelos discentes e todos os agentes de saúde, que buscam divulgar informações corretas e verdadeiras de modo a evitar problemas como o relatado acima (Souza $e t$ al. 2020).

É perceptível que os estudantes durante a realização do estágio e a pandemia passaram por inúmeros desafios e dificuldades, os quais residem tanto em problemas estruturais como pessoais, relativos as incertezas e inseguranças frente a essa realidade até então desconhecida por muitos. Porém é essencial ressaltar que tais alunos apresentados nos principais estudos, relataram o acompanhamento e o auxílio direto dos professores e supervisores de estágio, que contribuíam através do diálogo e da ampliação da visão do aluno sobre os conhecimentos necessários para sua atuação (Franklin, Vasconcelos \& Eduardo, 2020).

Além disso, é visível que mesmo diante das dificuldades muitos relatam em seus estudos como a realização do estágio contribui de forma efetiva na construção de um profissional mais preparado, ético e empático diante ao público atendido, evidenciando como a formação desses discentes apresentaram um crescimento pessoal, acadêmico e profissional (Souza et al. 2020). 


\section{Considerações Finais}

Diante das considerações apresentadas é perceptível que o momento vivenciado na atualidade devido a pandemia COVID-19 modificou o modo e a mentalidade da sociedade sobre cuidados com a saúde, empatia ao próximo e novas demandas sociais. O contexto atual provocou diversas reflexões, principalmente no campo da educação que necessitou reformular e adaptar suas metodologias de modo a promover a continuidade do ensino.

Dessa forma, ao longo da discussão notou-se que tais mudanças implicaram de forma efetiva dentro do curso de enfermagem, onde as aulas remotas foram adotadas para a continuidade da formação profissional e acadêmica. Do mesmo modo, houve uma flexibilização dos estágios, ficando sobre a optativa do discente realiza-los nesse momento.

Tais medidas trouxeram inúmeros problemas para os acadêmicos, no âmbito das aulas remotas verificou-se a falta de acesso e conhecimentos dos recursos, dificuldades de concentração e atenção, e outros problemas enfrentados tanto por discentes como docentes.

Já nas atividades referente ao estágio apresentaram-se nos estudos inúmeros relatos de estudantes do curso de enfermagem que presenciaram momentos de insegurança, medo, impotência, além de falta de acesso a equipamentos básicos e angústia e distanciamento das famílias com medo de contaminação.

É importante ressaltar que houve aspectos positivos diante desse momento, onde aqueles estudantes que se disponibilizaram a atuar frente a linha de frente dos hospitais vivenciaram situações de luta, alegria e superação, houve uma reflexão sobre a necessidade de atualização do ensino, de modo a compreender as contribuições benéficas da tecnologia e dos recursos digitais.

Em suma, é possível compreender que o momento atual é algo atípico e que todos tiveram que se reorganizar e adaptar ao novo normal, de modo que esse contexto pandêmico fez com que mudanças surgissem na sociedade revelando questões como a desigualdade social e econômica e a fragilidade de diversas esferas da sociedade.

\section{Referências}

Aquino, E. M. L., Silveira, I. M., Pescarini, J. M., Aquino, R., Souza Filho, J. A., Rocha, A. S., Ferreira, A., Victor, A., Teixeira, C., Machado, D. B., Paixão, E., Alves, F. J. O., Pilecco, F., Menezes, G., Gabrielli, L., Leite, L., Almeida, A. C. C., Ortelan, N., Fernandes, Q. H. R. F., Ortiz, R. J. F., Palmeira, R. N., Pinto Junior, E. P., Aragão, E., Souza, L. E. P. F., Barral Netto, M., Teixeira, M. G., Barreto, M. L., Ichihara, M. Y., \& Lima, R. T. R. S. (2020). Medidas de distanciamento social no controle da pandemia de COVID-19: potenciais impactos e desafios no Brasil. Ciência \& Saúde Coletiva, Salvador, 25, $2423-2446$. https://www.scielosp.org/article/csc/2020.v25suppl1/2423-2446/pt/.

Bastos, M. C., Canavarro, D. A., Campos, L. M., Schulz, R. S., Santos, J. B., \& Santos, C. F. (2020). Ensino remoto emergencial na graduação em enfermagem: relato de experiência na covid-19. Reme Revista Mineira de Enfermagem, Salvador, 24, 1-6. http://reme.org.br/artigo/detalhes/1495.

Bezerra, A. C. V., Silva, C. E. M., Soares, F. M. G., \& Silva, J. A. M. (2020). Fatores associados ao comportamento da população durante o isolamento social na pandemia de COVID-19. Ciência \& Saúde Coletiva, 252411-2421https://www.scielosp.org/pdf/csc/2020.v25suppl1/2411-2421/pt.

Bezerra, I. M. P. (2020). Estado da arte sobre o ensino de enfermagem e os desafios do uso de tecnologias remotas em época de pandemia do coronavírus. Journal Of Human Growth And Development, 30, 141-147, 14 abr. https://revistas.marilia.unesp.br/index.php/jhgd/article/view/10087/6379.

Bittencourt, R. N. (2020). Pandemia, isolamento social e colapso global. Revista Espaço Acadêmico, 19, 168-178. https://periodicos.uem.br/ojs/index.php/EspacoAcademico/article/view/52827.

Brasil. (2020). Portaria $n^{\circ} 343$, de 17 de março de 2020. Dispõe sobre a substituição das aulas presenciais por aulas em meios digitais enquanto durar a situação de pandemia do Novo Coronavírus - COVID-19. https://www.in.gov.br/en/web/dou/-/portaria-n-343-de-17-de-marco-de-2020 248564376.

Brasil. (2020). Portaria $\mathrm{n}^{\circ}$ 544, de 16 de junho de 2020. Dispõe sobre a substituição das aulas presenciais por aulas em meios digitais, enquanto durar a situação de pandemia do novo coronavírus - Covid-19, e revoga as Portarias MEC nº 343, de 17 de março de 2020, no 345 , de 19 de março de 2020, e no 473, de 12 de maio de 2020. https://www.in.gov.br/en/web/dou/-/portaria-n-544-de-16-de-junho-de2020261924872\#: :text=Disp\%C3\%B5e\%20sobre\%20a\%20substitui\%C3\%A7\%C3\%3o\%20das,12\%20de\%20maio\%20de\%202020. Acesso em: 22 abr. 2021.

Brasil, V. B. P., Mota, B. S., Costas, J. C., Pereira, M. T. F., Assis Filho, A. C., Carvalho, A. Q., Rocha, E. S. C., Souza, S. S., \& Pina, R. M. P. (2021). Programa "O Brasil Conta Comigo": experiência de estudantes de enfermagem das amazonas. Revista Eletrônica Acervo Saúde, 13, 1-6. https://acervomais.com.br/index.php/saude/article/view/5472.

Carneiro, P. R. C., Meira, J. L., Nascimento, L. R., Silveira, Z. M., Xavier, A. B., Soares, P. P., \& Santana, W. V. (2021). O ensino de enfermagem e os desafios do uso de tecnologias remotas em tempos de pandemia do coronavírus (COVID-19). Brazilian Journal Of Development, 7, 8667-8682. Disponível em: https://www.brazilianjournals.com/index.php/BRJD/article/view/23600. 
Dias, J. A. A., Dias, M. F. S. L., Oliveira, Z. M., Freitas, L. M. A., Santos, N. S. N., \& Freitas, M. C. A. (2020). Reflexões sobre distanciamento, isolamento social e quarentena como medidas preventivas da COVID-19. Revista de Enfermagem do Centro-Oeste Mineiro, 10, 1-8. http://seer.ufsj.edu.br/index.php/recom/article/view/3795.

Fernandes, J. D., \& Rebouças, L. C. (2013). Uma década de Diretrizes Curriculares Nacionais para a Graduação em Enfermagem: avanços e desafios. Revista Brasileira de Enfermagem, 66, 95-101, set. 2013. https://www.scielo.br/scielo.php?script=sci_arttext\&pid=S003471672013000700013.

Franklin, T.A., Vasconcelos, C. O., \& Eduardo, P.N. (2020). Contribuições do estágio não obrigatório para a formação do enfermeiro em meio à pandemia do novo coronavírus (covid-19): um relato de experiência. Brazilian Journal Of Development, Curitiba6, 71297-71304. https://www.brazilianjournals.com/index.php/BRJD/article/view/17152/13948.

Franzoi, M. A. H., \& Canduro, F. L. F. (2020). Atuação de estudantes de enfermagem na pandemia DE COVID-19. Cogitare Enfermagem, 25, 1-9, 26. https://revistas.ufpr.br/cogitare/article/view/73491/pdf.

Iser, B. P. M., Silva, I., Raymundo, V. T., Poleto, M. B., Trevisol, F. S., \& Bobinski, F. (2020). Definição de caso suspeito da COVID-19: uma revisão narrativa dos sinais e sintomas mais frequentes entre os casos confirmados. Epidemiologia e Serviços de Saúde, 29, 1-11. https://www.scielosp.org/pdf/ress/2020.v29n3/e2020233/pt.

Lima, S. É. R., Freitas, A. C. O., Silva, A. V. O., Araujo, J. M. G., Oliveira, S. F., \& Pereira, E. V. (2020). Ensino-aprendizagem em aulas remotas no contexto da pandemia por covid-19: dificuldades e potencialidades relatadas por acadêmicos de enfermagem. In: Souza., Luís Paulo Souza e (org.). COVID-19 no Brasil os múltiplos olhares da ciência para compreensão e formas de enfrentamento. (5a ed.) Atena, p. 145-153.

Lira, A. L. B. C., Adamy, E. K., Teixeira, E., \& Silva, F. V. (2020). Educação em enfermagem: desafios e perspectivas em tempos da pandemia COVID19. Revista Brasileira de Enfermagem, 73, 1-6. https://www.scielo.br/scielo.php?script=sci_arttext\&pid=S003471672020001400407\&tlng=en.

Malta, D. C., Szwarcwald. C. L., Barros, M. B. A., Gomes, C. S., Machado, I. E., Souza Junior, P. R. B., Romero, D. L., Lima, M. G., Damacena, G. N., Pina, M. F., Freiras, M. I. F., Werneck, A. O., Silva, D. R. P., Azevedo, L. O., \& Gracie, R. (2020). A pandemia da COVID-19 e as mudanças no estilo de vida dos brasileiros adultos: um estudo transversal, 2020. Epidemiologia e Serviços de Saúde, 29, 1-13. https://www.scielosp.org/article/ress/2020.v29n4/e2020407/pt/.

Ministério da saúde. (2021). Sobre a doença.: https://coronavirus.saude.gov.br/sobre-a-doenca.

Moretti, S. A., Guedes Neta, M. L., \& Batista, E. C. (2020). Nossas Vidas em Meio à Pandemia da COVID - 19: incertezas e medos sociais. Rev Enfermagem $e$ Saúde Coletiva, 4, 32-41. https://www.researchgate.net/profile/SarahMoretti/publication/342898913_ Nossas_Vidas_em_Meio_a_Pandemia_da _COVID_19_Incertezas_e_Medos_Sociais_Our_Lives_in_The_Midst_of_The_COVID_Pandemic_19_Social_Uncertainties_and_Fear/links/5f0c80b892851c 38a519c2c0/Nossas-Vidas-em-Meio-a-Pandemia-da-COVID-19-Incertezas-e-Medos-Sociais-Our-Lives-in-The-Midst-of-The-COVID-Pandemic-19-SocialUncertainties-and-Fear.pdf.

OMS. (2021). Folha informativa sobre COVID-19. https://www.paho.org/pt/covid19.

Oster, V. V., Loss, T., Almeida, B. L. C., Motta, M. S., \& Kalinke, M. A. (2020). Uso das tecnologias da informação e comunicação no processo de ensinoaprendizagem no período de pandemia do coronavírus. In: SOUZA., Luís Paulo Souza e (org.). COVID-19 no Brasil os múltiplos olhares da ciência para compreensão e formas de enfrentamento. (5a ed.), Atena. p. 140-145

Padilha, A. (2020). Brasil como um dos epicentros da pandemia. Interfaces da Covid 19: impressões multifacetadas do período de pandemia, 42-43. http://repositorio.unesc.net/bitstream/1/7809/1/Brasil\%20como\%20um\%20dos\%20epicentros\%20da\%20pandemia.pdf.

Peixoto, S. V., Souza, M. A. N., Mambrini, J. V. M., Andrade, F. B., Malta, D. C., \& Costa, M. F. L. (2020). Comportamentos em saúde e adoção de medidas de proteção individual durante a pandemia do novo coronavírus: iniciativa elsi-covid-19. Cadernos de Saúde Pública, 36, 1-14. https://www.scielosp.org/pdf/csp/2020.v36suppl3/e00195420/pt.

Ramos, T. H., Pedrolo, E., Santana, L. L., Ziesemer, N. B. S., Haeffer, R., \& Carvalho, T. P. (2020). O impacto da pandemia do novo coronavírus na qualidade de vida de estudantes de enfermagem. Revista de Enfermagem do Centro-Oeste Mineiro, 10, 1 11.http://www.seer.ufsj.edu.br/index.php/recom/article/view/4042.

Ribeiro, B. M. S. S., Darli, R. C. M. B., \& Martins, D. C. (2020). Ser docente do curso de enfermagem em trabalho remoto durante a pandemia da COVID19. Revista de Enfermagem da Ufpi, 9, 1-6. https://periodicos.ufpi.br/index.php/reufpi/article/view/622. Santos, S. S. C. (2006). Perfil de egresso de Curso de Enfermagem nas Diretrizes Curriculares Nacionais: uma aproximação. Revista Brasileira de Enfermagem, 59, $217-221$. https://www.scielo.br/scielo.php?pid=S0034-71672006000200018\&script=sci_arttext\&tlng=pt.

Silva, T. M. O., Silva, T. M. O., Souza, R. P., Silva, Y. P. Z., \& Macedo, S. A. (2020). Conceitos dos discentes de enfermagem sobre aulas remotas. Diálogos em Saúde, 1, . 47-61. https://periodicos.iesp.edu.br/index.php/dialogosemsaude/article/view/275.

Simões, A. L. B., Almeida, F. F., Sales, I. A. S., Rolindo, J. M. R., Silva, L. B. O., Lima, R. R. C., Bezerra R. M.; \& Pedrosa, S. M. (2020). Docência em enfermagem em tempos de pandemia pela COVID-19: relação docente-acadêmico e perspectivas institucionais futuras no ensino remoto. In: SEMINÁRIO DE ATUALIZAÇÃO DE PRÁTICAS DOCENTES, 29., Anápolis. Anais [...]. Anápolis: Unievangélica,. $52-57$. http://anais.unievangelica.edu.br/index.php/praticasdocentes/article/view/5791.

Souza, L. B., Schir, D. G., Soccol., K. L. S., Santos, N.O., \& Marchiori, M. R. C. T. (2020). Estágio curricular supervisionado em enfermagem durante a pandemia de coronavírus: experiências na atenção básica. Journal Of Nursing And Health, 10, 1-10, 17 . https://pesquisa.bvsalud.org/portal/resource/pt/biblio1104062 ?src=similardocs. 